\title{
Are You Responsible for Traffic Congestion? A Systematic Review of the So- cio-technical Perspective of Smart Mobility Services
}

\author{
Katharina Ebner \\ University of Hagen \\ katharina.ebner@fernuni-hagen.de
}

\author{
Patrick Mattes \\ University of Hagen \\ patrick.mattes@fernuni-hagen.de
}

\author{
Stefan Smolnik \\ University of Hagen \\ stefan.smolnik@fernuni-hagen.de
}

\begin{abstract}
A large amount of the pollution of modern cities is caused by individual transportation. Hence, many road users suffer from stress, emissions and noise. Smart mobility services can help improving the situation by distributing traffic more consistently across different routes, times, and transportation modes. These services comprise two dimensions, a technical and a socio-technical. The latter addresses the road user's role as data and knowledge provider and stresses the road user's role in actively contributing to relieved traffic. As such, road users display one of the strongest levers to sustainably relieve traffic both in terms of knowledge providers and traffic actors. Using a systematic analysis of 28 publications, we show that existing SMob services show several challenges related to the involvement of road users. We call for more research on SMob services that account for long-term user involvement e.g. by positively influences road users' practices and routines.
\end{abstract}

\section{Introduction}

A large amount of the pollution of modern cities is caused by daily shuttle transportation [40] that frequently leads to traffic jam, especially during rush hours. As a result, many road users suffer from an increased stress level that in addition to emissions and noise negatively affects their health [48]. Smart mobility (SMob) services can help improving the traffic situation by distributing traffic more consistently across different routes, times, and transportation modes [47]. Building on the work of Wolter, by SMob we refer to an intelligent, proactive and sustainable steering of urban traffic by the use of modern information technologies and the incorporation of road users with the objective to reduce energy consumption, emissions, noise, and stress of road users and residents. A key notion underlying our definition is that SMob comprises two perspectives, a technical and a socio-technical. The technical perspective addresses the use of stationary traffic sensors and traffic information systems that may communicate and exchange data with each other (e.g. in the Internet of things), or provide data for advanced, frequently realtime, traffic analyses used to relief traffic. The sociotechnical perspective, on the one hand, addresses the road user's role as data and knowledge provider (e.g. as mobile traffic sensor). On the other hand, it stresses the road user's crucial role in contributing to relieved traffic - the core issue we address.

Road users display one of the strongest levers to sustainably relieve traffic both in terms of knowledge providers and traffic actors making active use of SMob services [28, 45, 48]. In this paper, using a systematic literature review of 28 publications on SMob, we will show that existing SMob services lack active participation of road users thus impeding the unleashing of the full knowledge potential of SMob services. As a result, many SMob services suffer from weak adoption rates, especially in the long run [11]. Continuous involvement of users and their acceptance are, however, essential success factors for SMob services, because technological progress cannot by itself change and improve urban traffic [18]. Hence, in this paper we call for research on SMob that accounts for user knowledge and adapt to user contexts in a way that positively influences road users' practices and routines. Giving this background, we pursue the following research question: How does existing research account for the socio-technical perspective of SMob, i.e., the road user as crucial knowledge provider and actor who actively contributes to a relieved traffic?

\section{Theoretical background}

\subsection{Smart mobility}

We see SMob as one of six domains of a smart city [15]. This perspective allows us to draw inferences from our results to a higher level. The related SMob goals of accessibility, sustainability, innovativeness and safety also enables us to adequately address the socio-technical perspective of SMob and, hence, address our research question. Beyond this framing of SMob within a smart city, it is also important to differentiate SMob from mobility. In this context, Wolter [47] maintains that optimizing the 
usage of present mobility offers using modern information technologies makes mobility smart. This approach assigns "smartness" purely to the intelligence of users (i.e. smart usage), but ignores that also modern technologies can make technological environments act (more) intelligent, thus smarter, without user involvement. Lahmann [22] addresses this facet by stating that only when mobility-related data from different sources is being collected, aggregated, analyzed and evaluated, mobility can be said to be intelligent or smart. While this definition is broader, we hold that another important characteristic of SMob is proactiveness, i.e. steering traffic a way that actively reduces or even prevents traffic congestion [9, 39]. Summarizing these arguments, we define SMob as an intelligent, proactive and sustainable steering of urban traffic by the use of modern information technologies and the incorporation of road users with the objective to reduce energy consumption, emissions, noise, and stress of road users and residents.

\subsection{Traffic management systems and traffic information systems}

The terms Traffic Management System (TMS) and Traffic Information system (TIS) are sometimes used simultaneously, since both aim to avoid congestions within cities and reduce fuel consumption, gas emissions, or energy consumption. Generally, papers addressing TIS rather focus on matters of data collection and fusion $[6,8,24]$, while papers dealing with TMS rather focus on service delivery, or service usage [28, 37]. Depending on the authors, data processing is either ascribed to TIS or TMS (or sometimes both with different aggregation levels) [12, 16, 26]. Understanding this vagueness, Djahel et al. [11] structure the process underlying SMob services into five phases: (1) data sensing and gathering, (2) data fusion, (3) processing and aggregation, (4) data exploitation, and (5) service delivery. These authors maintain that TMS ensure higher accuracy in estimating traffic conditions, are able to efficiently manage the traffic, provide real-time road traffic simulation and ensure simplified and smith integration of existing systems [11]. Accordingly, a TMS covers the phases 3 to 5, while a TIS rather focuses on data sensing, gathering, and fusion (phases 1 and 2), but also often provides traffic data directly to users (phase 5). Furthermore, the data sensing itself is frequently excluded from TIS definitions, since it is performed by different sensors. Following this distinction, we define TMS to actively intervene traffic based on advanced and elaborated traffic analysis and forecasting by e.g. dynamic traffic signs, temporary opening of hard shoulders, or steering of travelling behaviour of individual users. Traffic information systems (TIS) on the other hand have a more informative character, thus passive impact, on traffic by providing users with information as to where traffic is congested or where accidents have occurred.

\subsection{Research framework}

Reflecting on our understanding of SMob as well as TMS and TIS, we build our literature review on the framework depicted in Figure 1. Our research framework incorporates the two perspectives of SMob already mentioned in the introduction. The technical perspective addresses the use of stationary traffic sensors and traffic information systems that may communicate and exchange data with each other, or provide data for advanced, frequently real-time, traffic analyses used to relief traffic. The sociotechnical perspective addresses both the road user's role as data and knowledge provider and as active contributor to relieved traffic (actor).

Following the process structure by Djahel et al. [11], the data sensing is performed by mobile and stationary sensors. Since mobile sensors are usually attached to human actors (e.g. smartphones, cars equipped with GPS, buses, taxis) or human actors act as conscious sensors themselves (e.g. by explicitly providing traffic information), we place this type of sensor on the socio-technical perspective. Next, a TIS gathers and fusions the data from stationary and mobile sensors. This data is either directly delivered to human traffic data consumers (i.e. road users who query information about current traffic) or by TMS for subsequent processing, aggregation, and exploitation with the aim to better route traffic.

We include traffic relief as central outcome into our research framework. By traffic relief, we refer to reducing traffic congestion and improving transfer speed, both of which will have a positive impact on energy consumption, emissions, noise, and stress of road users and residents. TMS have been shown to have a moderate impact on traffic compared to the impact potentials of road users. By steering traffic signs, shoulders, or speed limits TMS have been proven to successfully relief traffic. However, it is has been shown that road users actively acting on traffic information can relieve traffic to a significantly higher degree than can TMS [28, 45, 48]. By contrast, road users who remain relatively passive, i.e. only consume traffic data, have the least positive impact on traffic. Cheng et al. [8] have demonstrated that SMob services such as Google Maps, iOS Maps, or Waze help making travelling more convenient. However, they do not reduce road congestions, but only relocate them to other spots. 


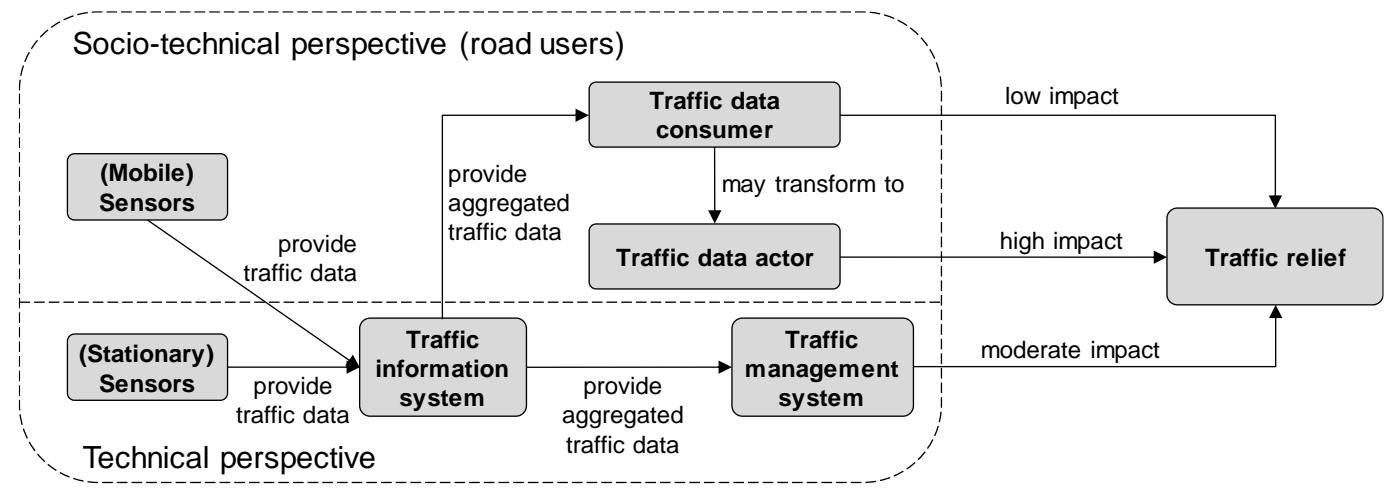

Figure 1: Research framework

\section{Research method}

Our research objectives are threefold: First, we seek to identify the current state of knowledge in the field of SMob services. Second, we aim to structure this knowledge according to our reference framework. Third, we wish to understand how previous research accounts for the road user as crucial knowledge provider and actor who actively contributes to a relieved traffic. In doing so, we seek to shed light on the impact of SMob services beyond mere issues of sensor data and analytical approaches and identify future research opportunities. In light of these goals, we conducted a structured literature review. Such a literature review helps aggregating and facilitating current knowledge as a basis for building new insights [35]. Methodologically, we rely on established guidelines for reviewing and synthesizing literature $[10,44]$. We focus our literature review on two perspectives related to SMob services, the technical (represented by TIS and TMS) and the sociotechnical perspective (represented by the road user).

Reviewing the more technical literature allows us to summarize SMob's basic constituents and to theoretically conceptualize their impact on relieving urban traffic. Concerning the literature addressing the socio-technical perspective of SMob, we decided in a first step to exclude literature focusing purely on public transportation or intermodal systems since we were interested in how existing research makes use of road users as sensors and how in turn road users' roles as consumers and actors are reflected. Further, looking at the socio-technical perspectives with the three different lenses of the road user (sensor, actor, consumer) makes it possible to consistently frame SMob as one field of action of smart cities [15] and offers different lenses on our research question [42].

\subsection{Literature selection}

As the basis for our review, we performed a keyword search in established databases for information systems and computer science (ACM digital library, AISeL, IEEE Xplore, Ebscohost Business Source Complete, Elsevier, Emerald Insight, SpringerLink). We particularly assured that the eight journals listed in the AIS Senior Scholar's Basket of Journals were covered, as these represent the top journals in our discipline. If necessary, we searched the journals archives separately (e.g. EJIS or JIT). Additionally, we took care that our disciplines major conferences (e.g. ICIS, ECIS, AMCIS, PACIS, ACIS, HICSS) would be covered [27]. We started our literature review by searching article abstracts, titles, and keywords for the strings "SMob OR SMob service," "mobility," "smart (city OR cities) AND (mobility OR transportation OR traffic OR road user)," and "connected car." In addition, backward search assured that we would not miss relevant articles published in other journals [44]. We did not include a formal time restriction in our search and included all papers that were published until September 2017. The resulting papers were directly checked for their relevance concerning fit with our research framework (e.g. some papers only mentioned SMob or included only an abstract or brief prototype sketches).

After this step, we had 99 publications that we used as basis for a more detailed analysis. Two of the authors discussed the relevance of each publication and eventually agreed on 38 publications for further consideration. For example, we included papers that reported on different TMS or TIS or SMob services, new or existing routing approaches, and intelligent and sustainable traffic steering. We excluded papers on e.g. car sharing, smart pavement and road maintenance, and papers that addressed professional (not individual) transportation (e.g. general logistic approaches, dispatching of service vehicles). Conference papers were only considered when the findings were not published in a subsequent journal article. For these remaining 38 publications, we performed 
an in-depth analysis and finally decided on a set of 28 articles. We excluded opinion papers, papers from the same author teams that were antecedent publications of subsequent articles or papers whose main focus turned out to be not SMob (e.g. one paper focused more on issues that may prevent using the Internet of things).

\subsection{Literature classification}

Our classification of the literature covers two complementary facets: (1) historical and temporal aspects, and (2) concept identification and analysis. In our analysis of the historical and temporal aspects, we only identified five publications until 2010, and a significant increase of publications after 2010 reflecting the still young discourse on SMob. Looking at the five publications $[4,6,23,29,34]$ in more detail also reflects how the overall discourse only slowly found its way into computer science and IS research since four of these publications result from logistics research. Only the paper by Bolla \& Davis [6] has been published on a traditional computer science conference. Since then, it took eleven years for the next paper to be published in a computer science context [7]. As of today, the discourse found its way into information systems research, which increasingly starts focusing the SMob user as main driver of traffic relief. Figure 2 provides an overview of the identified publications' distribution in five-year intervals.

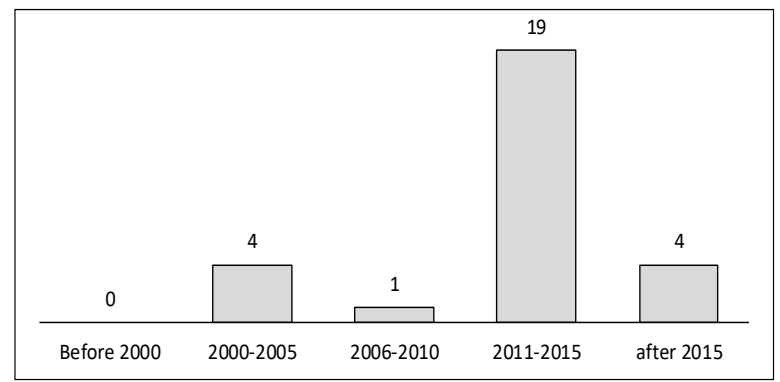

Figure 2: Overview of the identified articles by year

For our concept identification and analysis, we employed a two-stage process to systematically categorize the final list of papers. In the first stage, we performed a concept-centric analysis [44] around the categories of SMob services shown in Figure 1. The resulting concept matrix can be found in Table 2 . In the second stage, we specifically focused on two additional aspects. First, we wanted to gain a richer understanding of the nature of the relationships between the concepts. For example, instead of merely searching for evidence that the user as actor has the highest impact on traffic relief, we aimed at understanding how this effect unfolds [46]. Second, in light of the process underlying our research framework (from data gathering, to data analysis and processing, to service delivery), we were particularly interested in the transitions between the various phases; that is, how the mere traffic data and the road users' knowledge is transferred into SMob services, how these services are delivered to the road user, and how traffic would be relived from this process. This analysis and classification of the papers was initially performed by one researcher and then reviewed by one additional researcher. We also used axial coding to build a larger understanding of the network of concepts and derive a set of research opportunities [30, 46]. While these opportunities build on the relationships described above, they go beyond them by proposing specific research avenues that may substantially extend our understanding and perspectives of SMob in future research. This way, our work not only synthesizes and integrates the current state of SMob research, but also proposes a way forward.

\section{Review}

The aim of this chapter is to provide an overview into the current state of research on SMob. To that end, we first discuss the state of research concerning TMS and TIS (i.e. the technical perspective of SMob) and second discuss the different roles that have been ascribed to the user by previous research (i.e. the socio-technical perspective). Building on the insights from these analyses, we will conclude the section with a discussion and agenda for future research.

\subsection{General findings}

The classification of the papers according to our research framework from Figure 2 can be found in Table 2. The analysis of the papers we identified in our literature search resulted in several interesting insights concerning the state of SMob research. Before we discuss the various categories in detail, we wish to highlight some of the more general findings from our analyses.

Table 1: Identified papers and their research perspective

\begin{tabular}{|l|l|l|l|l|l|l|}
\hline Source & Type of publication & TMS & TIS & User as sensor & User as consumer & User as actor \\
\hline$[1]$ & Conference & & & X & X \\
\hline
\end{tabular}




\begin{tabular}{|c|c|c|c|c|c|c|}
\hline Source & Type of publication & TMS & TIS & User as sensor & User as consumer & User as actor \\
\hline$[2]$ & Conference & & $\mathrm{X}$ & $\mathrm{X}$ & & \\
\hline [4] & Journal & & & & $\mathrm{X}$ & \\
\hline$[5]$ & Journal & & & & $\mathrm{X}$ & \\
\hline [6] & Conference & & $X$ & $\mathrm{X}$ & & \\
\hline$[7]$ & Conference & & $\mathrm{X}$ & $\mathrm{X}$ & & \\
\hline$[11]$ & Journal & $\mathrm{X}$ & $\mathrm{X}$ & & & \\
\hline$[12]$ & Conference & $\mathrm{X}$ & $\mathrm{X}$ & & $\mathrm{X}$ & \\
\hline$[14]$ & Journal & & $\mathrm{X}$ & & $\mathrm{X}$ & \\
\hline$[16]$ & Journal & $\mathrm{X}$ & $X$ & & $\mathrm{X}$ & \\
\hline [17] & Conference & & & & & $X$ \\
\hline [19] & Conference & & $\mathrm{X}$ & $\mathrm{X}$ & & \\
\hline$[20]$ & Conference & $\mathrm{X}$ & $\mathrm{X}$ & $\mathrm{X}$ & & \\
\hline [23] & Journal & $\mathrm{X}$ & & & & \\
\hline [24] & Conference & & $\mathrm{X}$ & $\mathrm{X}$ & $\mathrm{X}$ & \\
\hline [25] & Conference & & & & & $\mathrm{X}$ \\
\hline$[26]$ & Conference & $\mathrm{X}$ & $\mathrm{X}$ & $\mathrm{X}$ & $\mathrm{X}$ & \\
\hline$[28]$ & Conference & $\mathrm{X}$ & & & $\mathrm{X}$ & \\
\hline$[29]$ & Conference & & $\mathrm{X}$ & & $\mathrm{X}$ & \\
\hline [31] & Conference & $\mathrm{X}$ & & & $\mathrm{X}$ & \\
\hline$[32]$ & Conference & & & & $\mathrm{X}$ & $\mathrm{X}$ \\
\hline [33] & Journal & & & & $\mathrm{X}$ & \\
\hline [34] & Journal & & & & $\mathrm{X}$ & $\mathrm{X}$ \\
\hline$[36]$ & Conference & & & & $\mathrm{X}$ & $\mathrm{X}$ \\
\hline$[37]$ & Conference & $\mathrm{X}$ & & & & \\
\hline$[38]$ & Conference & & $\mathrm{X}$ & $\mathrm{X}$ & $\mathrm{X}$ & \\
\hline [39] & Journal & & $X$ & & & \\
\hline [41] & Conference & & $\mathrm{X}$ & & $\mathrm{X}$ & \\
\hline Total & & 9 & 15 & 8 & 17 & 6 \\
\hline
\end{tabular}

A major proportion of research papers focus on the technical perspective of SMob and within this perspective a higher number of research papers target traffic information systems than TMS. A second finding is that no research paper combined a traffic management system with the user as an actor. The same result occurs when observing research papers that deal with traffic information systems, as they also don't consider the user as an actor.

Observing the socio-technical perspective it can be noted that again no paper focuses on all three aspects of a road user at the same time. Out of those papers that focus on two of the three categories at the same time, a major proportion is theoretical and only focus on the user and don't integrate him into actively influencing the traffic in order to relief it. A key finding of this literature review was to observe that out of all analysed data only a minor fraction of papers focused on the user as an actor. The main outcome was to figure out that a majority of those papers where theoretical and did not bring out a prototype or result which would actively solve the problem of traffic congestion by targeting road users. It is also noticeable that no research paper focused on a holistic solution by looking at the problem from all sides of interests.

\subsection{Technical perspective}

Djahel et al. [11] evaluate different routing approaches for smart parking. While these authors acknowledge the relevance of considering the consumer of a SMob solution, their main research interest is on architecture, safety, sustainability/energy awareness, efficiency, reliability and security, and innovative services. Though this gives an insight into the technology, it has not been focused on the user as an actor or a consumer. Lam \& Huang [23] differ as their approach is more user centric. Their aim is to filter out an algorithm that displays why people travel and what their short-term and long-term travel demands are and how this can be predicted better. Here 
a user is somehow considered though the main focus is not the user but how the traffic management system can deliver more information and which algorithm can be used for that.

To determine how dynamic a traffic management system can be designed, Salama et al. [37] describe a system that uses photoelectric sensors to make traffic lights intelligent. This can be of immense use for emergency cases and for predictable events (i.e. pilgrim travels to Makkah) that can cause major traffic congestion. This approach again is only technical and no interaction with the user can be seen. Other approaches also use dynamic sensors called floating car data and integrate them into the traffic management system $[2,12]$. To a certain extend this can be seen as an integration of the user as a sensor, however floating car data is being generated by hardware which is being installed into a car. Therefore, the car itself is a sensor and provides for example GPS location to the server.

The differentiation between a mere information system and a more complex management system has to be clear as there are many research approaches that target information systems. All these research papers focus on traffic management or traffic information systems only and do barely put into account a user at all. However, there are papers that do so as there are researchers that focus on the two aspects of such a system: the user and the technical set up. So far, the analysed research papers focused on either only the technical setup and functionality of a traffic management or traffic information system without taking into account a user (no matter as sensor, consumer or actor) at all, or they only see the user as sensor.

\subsection{Socio-technical perspective}

A majority of the relevant research papers focus on the technical perspective, not without acknowledging the fact that a user has to be integrated. In the end, the data that is generated shall be used to inform road users and, if possible, make them actively demand information and follow instructions. Electric cars are more present in nowadays traffic and therefore one information which users will demand might be where the next charging stations are [39]. A user as an actor then has to be discussed as he will later be the one to actively use the information that is being provided, to example be navigated (not intelligently) to the next charging station.

An already discussed solution is to use floating car data in order to display traffic conditions [2, 12]. According to our framework, using mobile data is part of the socio-technical perspective but still not human-centric enough but it is a first approach to integrate road users into the traffic relief management. Smartphones contain many useful hardware such as accelerometer, gyroscope, and rotation vector sensors [19] which can help to create a speed profile or even speed traces. Smartphone data can also be used to estimate traffic conditions using OD-matrices $[6,7]$. It is even possible to integrate users as sensors into a traffic management system by using inductive magnetic sensing and WIFI scanning [20]. Their work focuses rather on taxi drivers than individual users and therefore is out of scope for our research. In most identified research papers a common approach is to target the technical perspective and to discuss technical issues, but in order to be successful, drivers have to follow the instructions of a TMS. Nonetheless a profound discussion of user interaction is not being carried out.

One of the major reasons to introduce SMob services is to ease traffic congestions and to reduce travel time. Therefore one focus has to be to figure out why people travel [23], carry out preference surveys to figure out travel time variability [14] and focus on reducing travel time in general [26]. In conclusion, it is that smart navigation represents a powerful and cost-efficient tool, which, together with others (e.g., use of public transportation, etc.), can combat the increase in traffic congestion in urban areas [26]. It is important to understand the driver before setting up a system that no one uses, therefore other researchers focus on decision taking when being routed dynamically [41].

As displayed in our research framework it is of our understanding that the road user as a traffic data actor has the highest impact on traffic relief. Therefore we have to understand the driver's navigation behaviour [24]. To personalize navigation devices is a solution that can be presented when the user has been understood. A fairly experimental approach has been given by Liu et al. [28] who combined all ideas so far and introduce a ready-to-use application that focuses on individual re-routing in order to prevent new congestions to occur. Their system, called Themis, has been tested by using it with taxi drivers and having carried out a deeper test-phase, they claim that since their program Themis reduces global traffic volume and travel time, it could be useful to prevent congestions and reduce pollution. The use of commercial vehicles to collect data is fairly innovative as more and more taxis, delivery cars, buses and trucks are being equipped with data and therefore using them instead of stationary data provides new data for new dynamical systems [29]. Mainly the focus is to have a driver that not only is being used as sensor, but also as consumer. 
More research is being carried out, however the focus is mainly on the systems itself and not on the user as consumer or even as actor. The approaches discussed assume that if a new system is being introduced it will automatically be used by the target group. It is of our interest to set a focus on the user as an actor and define this as someone who actively uses applications which navigate dynamically and intelligently. As it has been displayed the research approaches which have been discussed so far have mostly targeted the technical aspect of a traffic management system or with the user as a (mobile) sensor.

When setting up SMob services there are potential conflicts with the user and therefore they have to be integrated into the concept-phase [1]. In an open research it has been discussed to integrate citizens in smart city projects [17]. SMob services, as one pillar of smart city, also have to take into account the relevance of the user in order to be long-lasting and successful. By analysing the research papers, it can be stated that smart cities have to be designed human centred and that humans as actors are more important than a perfectly intelligent traffic management tool. Not only the system itself has to work but also applications that focus on the human and the interaction with those individuals in order to flourish smart cities [36].

Another call for research states that a transportation system consists of two pillars: public transportation and individual cars [25]. Users then shall use applications of their smartphone to change between transportation modes and route spontaneously. As there are already numerous applications that focus on this system, it has come to their attention that human dimensions have rarely been addressed and that this has to be more of a focus. First attempts to have a user actively involved in using applications is by Mitsopoulou, Kalogeraki [32]. They target drivers in greater cities who seek parking spots and can use their application in order to find the best suitable parking spot. Several models of usage have been designed and it is a first attempt of actively trying to incorporate the user and give him benefits when using the application. Less congestion and less frustration would be the result if following their parking guidance advice.

Up to this point it has come clear that research attempts that target the user as an actor state that first of all citizens and/or drivers have to be integrated when setting up new services. Moreover other researches focused on technical solutions but critical research shows that when designing new applications, ethical issues have to be considered too [36]. But not only are those issues important, it has to be discussed to which extent such services are feasible.
[33] claim that individual transport results in congestions because a large number of people give priority to their own comfort when travelling. They seek to implement a balance between individual transport and the importance of society and the environment. According to Okuda et al. [33]it cannot be a solution to focus on restrictions on mobility by setting up for example congestions zones and vehicle bans. Overall they want to optimize specific forms of transportation such as trains and cars and seek to combine those in order to ease traffic congestion [33].

\section{Discussion}

Upon our structured review of the literature, we noted that with respect to SMob services, research has made a significant process within the last few years. Today, a profound knowledge and understanding of the functionality of sensors, mobile $[6,38]$ and stationary [32] enables the design of powerful SMob services. Having that said, we also figured out that research on the proactive processing of traffic data and on the provision of SMob services to end-users is still at its beginning. Regarding the data processing and analysis, we find that many concepts are still in a prototyping phase and have not been evaluated or implemented in a real-world setting. Accordingly, the amount of conceptual or design papers is relatively high in our literature sample, while empirical papers account for only a very small portion of the overall literature. Hence, future researchers should strive to validate existing prototypes and in different empirical contexts.

Furthermore, considering the socio-technical perspective, most attention has been drawn on the road user as passive participant of traffic, i.e. as consumer of traffic data. The question of how a consumer can be transformed into a continuous actor who actively contributes to traffic relief has hardly been addressed so far. This finding mirrors the calls for research from other researchers for more user-centricity in the design of SMob services in order to assure long-term participation in traffic relief by road users [17, 25]. Among the few papers that have started addressing this research need, we wish to highlight a few approaches that seem particularly fruitful to us.

The first approach is the work of Leontiadis et al. [26] who suggest the most holistic SMob service we identified in our concept-centric analysis. By animating road users via social applications to actively consuming intelligent routing guidance systems, they are able to capture, aggregate, and process user-provided trip-chain data. In doing so, this paper is one of the first to make systematic use of road users' knowledge and fundamentally base traffic scheduling on this 
knowledge and also one of very few that uses tripchain data to perform advanced traffic analyses. Still, the authors stay silent on how their system's use could be sustained in the long-term.

A starting point to address this latter aspect can be found in the works of Cheng et al. (2016) and Sakamoto \& Nakajima (2015). By employing elements from social computing [8] and gamification [36], these authors acknowledge the presence and importance of human interaction when implementing SMob services. They maintain that both, the app design and the implementation process have to consider the specific context of individual transportation and long-term use of information technologies. Given that social computing and gamification have proven appealing for users of all social classes [21, 43] and are able to create positive emotions and attitudes towards system use in the long run [3, 13], we suggest that future researchers should build on these concepts in their design of SMob services. Finally, it should be noticed that nowadays, the service delivery frequently operates via SMob services that not only deliver traffic services, but also support an open data sensing and gathering. As a result, the traditional boundaries between TMS and TIS blur, raising concerns on data reliability, architectural clarity, and outcome responsibility. Only a few authors so far have started addressing the resulting consequences [25, 26]. For instance, the gathering and analysis of the traffic knowledge of a user (i.e. not just information on actual traffic, but also more general knowledge on road maintenance status, relevant events that may impact traffic, etc.) is still challenging. On the one hand, as mentioned in the introduction, many systems do not allow users to provide open-issued, unstructured information. On the other hand, the analysis capabilities of most TIS and TMS do not allow new knowledge to emerge from the data and information available. As a result, while virtually all authors ascribe a very potential to SMob services leveraging the users' knowledge, their full potential has not yet been leveraged. We summarize our findings along with the related research opportunities in Table 2.

Table 2: Summarized research opportunities

\begin{tabular}{|c|c|}
\hline Research Agenda & Description \\
\hline $\begin{array}{l}\text { Validation of } \\
\text { existing research }\end{array}$ & $\begin{array}{l}\text { - Research on SMob services is still at its beginning. Many papers are conceptual in nature or } \\
\text { still in a prototyping phase. } \\
\text { - Application of existing prototypes and concepts in different empirical contexts is necessary to } \\
\text { validate the existing body of knowledge. }\end{array}$ \\
\hline $\begin{array}{l}\text { Transformation } \\
\text { of user from con- } \\
\text { sumer to actor }\end{array}$ & $\begin{array}{l}\text { - Most attention has been drawn on the road user as passive participant of traffic. } \\
\text { - More user-centricity in the design of SMob services is needed in order to assure long-term } \\
\text { participation in traffic relief by road users. }\end{array}$ \\
\hline $\begin{array}{l}\text { Lacking gather- } \\
\text { ing of data on trip } \\
\text { chains }\end{array}$ & $\begin{array}{l}\text { - Only very few researchers make systematic use of road users' knowledge on trip-chains and } \\
\text { use this knowledge to perform advanced traffic analyses. } \\
\text { - Future SMob solutions should actively extend their analytical range to allow the users' } \\
\text { knowledge to shape traffic scheduling to a significant higher degree. }\end{array}$ \\
\hline $\begin{array}{l}\text { Lacking long- } \\
\text { term adoption of } \\
\text { SMob services }\end{array}$ & $\begin{array}{l}\text { - Hardly any publication on SMob considers the specific context of individual transportation } \\
\text { and long-term use of information technologies. } \\
\text { - Future researchers should develop viable concepts to sustain the long-term use of SMob ser- } \\
\text { vices. First fruitful approaches building on e.g. social computing and gamification have been } \\
\text { made. }\end{array}$ \\
\hline $\begin{array}{l}\text { Blurring of } \\
\text { boundaries be- } \\
\text { tween TMS/TIS }\end{array}$ & $\begin{array}{l}\text { - Since service delivery frequently operates via SMob services that also support data sensing } \\
\text { and gathering, the traditional boundaries between TMS and TIS blur. } \\
\text { - Future researchers should address the resulting consequences from this blurring on data relia- } \\
\text { bility, architectural clarity, and outcome responsibility. }\end{array}$ \\
\hline
\end{tabular}

\section{Conclusion}

In this paper, we performed a literature analysis on the current state of SMob research. We found that in light of an increasing supply of SMob services, researchers increasingly acknowledge the role of the sociotechnical perspective in understanding how traffic relief can actually be attained. However, there is still a significant gap in research addressing by which mechanisms road users can be transformed from mere SMob service consumers towards continuous and engaged actors that actively contribute to relieving traffic. Especially the challenge of long-term engagement of road users is one of the most pressing challenges of existing SMob services, both in terms of environmental and investment-related sustainabil- 
ity. We therefore wish to encourage future researchers to suggest viable concepts that may sustain road users' involvement and interest in actively relieving urban traffic. From a more technical perspective, we found that road users' advanced traffic knowledge as of today plays only a subordinate role in existing TIS and TMS. Also, the opportunities related to advanced analytical approaches are still at an early stage and should be further developed.

Summing up, our research contributes to research and practice by shedding light on how viable smart traffic services for modern cities should be conceptualized, designed and implemented. Furthermore, it contributes to an improved understanding of SMob service adoption by highlighting that the system design should be oriented towards the actual context and demands of road users and leverage their knowledge. We show that only this particular sociotechnical aspect of road user technology adoption can generate long-term environmental and economic benefits by sustaining the success of new SMob services.

Beyond these contributions, our study has limitations. First, the literature search and classification process involved might be biased owing to our choice of keywords and the subjective interpretations and preferences that influenced paper selection and classification. Thus, we cannot rule out that some publications that other researchers may deem as relevant were not considered here. Second, we decided to intentionally exclude literature on public and intermodal transportation since we were particularly interested on the sociotechnical aspects of individual transportation. However, in a next step, we intend to systematically and stepwise broaden our review scope to understand, if concepts suggested by research on public and intermodal transportation could also apply to individual transportation. Third, our research framework somewhat grounds in the SMob process as suggested by Djahel et al. (2015) and the differentiation between a technical and a sociotechnical layer. This particular framing impacts our view on and understanding of existing research. Future researchers who may analyze the existing body of knowledge with different lenses may thus come up with different interpretations and insights.

\section{References}

[1] Ali-Vehmas, T. and T. Casey, "Examining possible value system transitions: The case of smart mobility services", 48th Hawaii International Conference on System Sciences, 2015, pp. 4366-4375.

[2] Alrefaie, M.T., "Demo: Road Speed Profile: From GPS Traces to Real-time Traffic Speed", MobiHoc, 2014, pp. 407-408.
[3] Bagayogo, F.F., L. Lapointe, and G. Bassellier, "Enhanced use of IT: A new perspective on post-adoption", Journal of the Association for Information Systems, 15(7), 2014, pp. 361-387.

[4] Ben-Elia, E., I. Erev, and Y. Shiftan, "The combined effect of information and experience on drivers' routechoice behavior", Transportation(35), 2008, pp. 165-177. [5] Ben-Elia, E., R. Ishaq, and Y. Shiftan, "'If only I had taken the other road..."': Regret, risk and reinforced learning in informed route-choice", Transportation(40), 2013, pp. 269-293.

[6] Bolla, R. and F. Davoli, "Road Traffic Estimation from Location Tracking Data in the Mobile Cellular Network", Wireless Communications and Networking Conference, 2000, pp. 1107-1112.

[7] Calabrese, F., G. Di Lorenzo, L. Liu, and C. Ratti, "Estimating Origin- Destination Flows Using Mobile Phone Location Data", PERVASIVE computing, 2011, 15361268 .

[8] Cheng, Z., M.-S. Pang, and P. Pavlou, "On Intelligent Transportation Systems and Road Congestion", Thirty Seventh International Conference on Information Systems, 2016.

[9] Colak, S., L.P. Alexander, B.G. Alvim, S.R. Mehndiratta, and M.C. Gonzalez, "Analyzing Cell Phone Location Data for Urban Travel", Journal of the Transportation Research Board, 2526, 2015, pp. 126-135.

[10] Cooper, H.M., Synthesizing Research - A Guide for Literature Reviews, 3rd edn., Sage Publications, 1998.

[11] Djahel, S., R. Doolan, G.-M. Muntean, and J. Murphy, "A Communications-Oriented Perspective on Traffic Management Systems for Smart Cities: Challenges and Innovative Approaches", IEEE Communications Surveys \& Tutorials, 17(1), 2015, pp. 125-151.

[12] Ebendt, R., A. Sohr, and L.C. Touko-Tcheumadjeu, "Dynamische Neuplanung der Touren von Express Trucks unter Einbeziehung einer FCD-basierten Verkehrslage.", Multikonferenz Wirtschaftsinformatik 2012 : Tagungsband der MKWI 2012, 2012, pp. 124-136.

[13] Ebner, K., S. Smolnik, and G. Bassellier, "From Efficiency to Innovativeness: Post-Adoption IT Use Types and Related Outcomes", Proceedings of the Pre-ICIS DIGIT 2016 Workshop "Technology Adoption, Use and Diffusion Research at the Crossroad", Dublin, Ireland, 11 Dezember. 2016.

[14] Gan, H. and Y. Bai, "The effect of travel time variability on route choice decision: a generalized linear mixed model based analysis", Transportation(41), 2014, 339.350. [15] Giffinger, R., C. Fertner, H. Kramar, and Kalasek, R., Pichler-Milanovic, N. \& Mejers, E., "Smart cities. Ranking of European medium-sized cities: Final repor", Centre of Regional Science, 2007.

[16] Goel, P., R.H. Goudar, R. Malik, R. Singh, and N.K. Singh, "Localization based intelligent traffic management system", The Society for Reliability Engineering, Quality and Operations Management (SREQOM), India and The Division of Operation and Maintenance, Lulea University of Technology, 2015. 
[17] Gooch, D., G. Kortuem, A. Wolff, and R. Brown, "Reimagining the Role of Citizens in Smart City Projects", UBICOMP/ISWC, 2015, pp. 1587-1594.

[18] Hollands, R.G., "Will the real smart city please stand up?", City, 12(3), 2008, pp. 303-320.

[19] Jahangiri, A. and H. Rakha, "Applying Machine Learning Techniques to Transportation Mode Recognition Using Mobile Phone Sensor Data", IEEE Transactions on Intelligent Transportation Systems, 16(5), 2015, pp. 24062417.

[20] Kostakos, V., T. Ojala, and T. Juntunen, "Traffic in the smart city: Exploring the potential of city-wide sensing to augment a traffic control center", IEEE Internet Computing, 2013.

[21] Krastel, Z., G. Bassellier, and J. Ramaprasad, "Music is Social: From Online Social Features to Online Social Connectedness", International Conference on Information Systems, Fort Worth, Texas, USA, December 13-16. 2015. [22] Lahmann, H., "Gesellschaftliche Konfliktlinien im Kontext von Big Data am Beispiel von Smart Health und Smart Mobility", Diskussionspapier im Projekt „Braucht Deutschland einen Digitalen Kodex?", 2015.

[23] Lam, W.H.K. and H.-J. Huang, "Combined Activity/Travel Choice Models: Time-Dependent and Dynamic Versions", Networks and Spatial Economics, 2003, pp. 323-347.

[24] Landau, A., D.C. Mattfeld, and J.F. Ehmke, "MULTIPERSPECTIVE DATA ANALYSIS OF DRIVERS' NAVIGATION BEHAVIOUR", ECIS Proceedings, 2014.

[25] Lenz, B. and D. Heinrichs, "What Can We Learn from Smart Urban Mobility Technologies?", PERVASIVE computing, 2017, pp. 84-86.

[26] Leontiadis, I., G. Marfia, D. Mack, G. Pau, C. Mascolo, and M. Gerla, "On the Effectiveness of an Opportunistic Traffic Management System for Vehicular Networks", IEEE Transactions on Intelligent Transportation Systems, 12(4), 2011, pp. 1537-1548.

[27] Levy, Y. and T.J. Ellis, "A Systems Approach to Conduct an Effective Literature Review in Support of Information Systems Research", Informing Science Journal, 9, 2006, pp. 181-212.

[28] Liu, R., H. Liu, D. Kwak, Xiang, Y., Borcea, C., B. Nath, and L. Iftode, "Themis: A Participatory Navigation System for Balanced Traffic Routing", IEEE Vehicular Networking Conference (VNC), 2014, pp. 159-166.

[29] Lorkowski, S., O. Mieth, K.-U. Thiessenhusen, D. Chauhan, B. Passfeld, and R.-P. Schäfer, "TOWARDS AREA-WIDE TRAFFIC MONITORINGAPPLICATIONS DERIVED FROM PROBE VEHICLE DATA", Eighth International Conference on Applications of Advanced Technologies in Transportation Engineering (AATTE), 2004, pp. 389-394.

[30] Miles, M.B. and A.M. Huberman, Qualitative Data Analysis: An Expanded Sourcebook, 2nd edn., Sage Publications, Thousand Oaks, 1994.

[31] Misbahuddin, S., J.A. Zubairi, A. Saggaf, J. Basuni, S. A-Wadany, and A. Al-Sofi, "IoT Based Dynamic Road Traffic Management for Smart Cities", 12th International conference on High-capacity optical Networks and Enabling/Emerging Technologies, 2015.
[32] Mitsopoulou, E. and V. Kalogeraki, "Efficient Parking Allocation for SmartCities", PETRA, 2017, pp. 265-268.

[33] Okuda, T., S. Hirasawa, N. Matsukuma, T. Fukumoto, and A. Shimura, "Smart Mobility for Smart Cities", Hitachi Review, Vol. 61, 2012, pp. 141-146.

[34] Peeta, S. and J.W. Yu, "A Hybrid Model for Driver Route Choice Incorporating En-Route Attributes and RealTime Information Effects", Networks and Spatial Economics(5), 2005, pp. 21-40.

[35] Rowe, F., "What literature review is not: diversity, boundaries and recommendations", European Journal of Information Systems, 23(3), 2014, pp. 241-255.

[36] Sakamoto, m. and T. Nakajima, "Gamifying Smart City Services to Flourish Our Society", UBICOMP/ISWC, 2015, pp. 1515-1518.

[37] Salama, A.S., B.K. Saleh, and M.M. Eassa, "Intelligent Cross Road Traffic Management System (ICRTMS)", 2nd International Conference on Computer Technology and Development, 2010, 27-31.

[38] Sassi, A. and F. Zambonelli, "Coordination Infrastructures for Future Smart Social Mobility Services", Intelligent Transportation Systems, 2014, pp. 78-82.

[39] Schmidt, W., S. Borgert, A. Fleischmann, L. Heuser, C. Müller, and I. Schweizer, "Smart Traffic Flow", HMD Praxis der Wirtschaftsinformatik, 52(4), 2015, pp. 585596.

[40] Schubert, M., T. Kluth, G. Nebauer, R. Ratzenberger, S. Kotzagiorgis, B. Butz, W. Schneider, and M. Leible, Verkehrsverflechtungsprognose 2030, 2014.

[41] Soeffker, N., M.W. Ulmer, and D.C. Mattfeld, "Problem-Specific State Space Partitioning for Dynamic Vehicle Routing Problems", Multikonferenz Wirtschaftsinformatik (MKWI)(Band 1), 2016, pp. 229-240.

[42] Sylvester, A., M. Tate, and D. Johnstone, "Beyond synthesis: re-presenting heterogeneous research literature", Behaviour \& Information Technology, 32(12), 2013, pp. 1199-1215.

[43] Tomaselli, F., O. Sanchez, and S. Brown, "How to Engage Users through Gamification: The Prevalent Effects of Playing and Mastering over Competing", International Conference on Information Systems, Fort Worth, Texas, USA, December 13-16. 2015.

[44] Webster, J. and R.T. Watson, "Analyzing the past to prepare for the future: Writing a literature review", MIS Quarterly, 26(2), 2002, pp. 13-23.

[45] Willing, C., T. Brandt, and D. Neumann, "Intermodal Mobility", Business \& Information Systems Engineering, 59(3), 2017, pp. 173-179.

[46] Wolfswinkel, J.F., E. Furtmueller, and C.P.M. Wilderom, "Using grounded theory as a method for rigorously reviewing literature", European Journal of Information Systems, 22(1), 2013, pp. 45-55.

[47] Wolter, S., "Smart-Mobility-Intelligente Vernetzung der Verkehrsangebote in Großstädten", Zukünftige Entwicklungen in der Mobilität, 2012, pp. 527-548.

[48] Zhou, X., X. Chen, and T. Zhang, "Impact of Megacity Jobs-Housing Spatial Mismatch on Commuting Behaviors: A Case Study on Central Districts of Shanghai, China", Sustainability, 8(2), 2016, p. 122. 